\title{
ARTE, CULTURA Y VIDA COTIDIANA EN EL CONURBANO (PROVINCIA DE BUENOS AIRES, ARGENTINA) \\ NOTAS DESCRIPTIVO-ANALÍTICAS SOBRE LA INTERSECCIÓN ENTRE DESIGUALDAD Y TERRITORIO
}

\section{ART, CULTURE AND DAILY LIFE IN THE CONURBANO (PROVINCE OF BUENOS AIRES, ARGENTINA) DESCRIPTIVE-ANALYTICAL NOTES ON THE INTERSECTION BETWEEN INEQUALITY AND TERRITORY}

\author{
María Florencia Blanco Esmoris \\ (CIS-CONICET/IDES, Argentina) \\ flor.blancoesmoris@gmail.com
}

Recibido: 25 febrero 2020 Aceptado: 16 marzo 2020

\begin{abstract}
Resumen: El presente artículo se propone reflexionar en torno a la discusión entre arte y ciudad a partir de la producción cultural que emerge en las en las periferias urbanas, en particular, aquella que se origina en los Partidos del Gran Buenos Aires, Argentina. Para tal propósito, analizo diversas prácticas artísticas de una organización social y cultural la Biblioteca Popular La Cárcova -, específicamente sus intervenciones públicas. El objetivo es presentar las formas particulares en las que se encarna el arte en estos territorios. Para ello presento la Provincia de Buenos Aires y algunos estudios sobre estas desde las ciencias sociales. En segundo lugar, repongo el contexto de la organización. Y, por último, las tensiones analíticas y empíricas en las producciones e intervenciones de los actores elegidos. El fin último de este trabajo es contribuir a los debates respecto a las producciones artísticas en las periferias urbanas intentando trascender a aquellos que agotan el entendimiento sobre el arte bajo las concepciones de "lo estético" y "lo legítimo".
\end{abstract}

Palabras clave: conurbano; vida cotidiana; arte; desigualdad; Argentina

\begin{abstract}
This article seeks to reflect on the discussion between art and city based on the cultural production that emerges in the urban peripheries. In particular, the ones originated in Greater Buenos Aires, Argentina. For this purpose, I analyse a variety of
\end{abstract}


artistic practices of a social and cultural organization known as Popular Library La Cárcova. The aim is to present forms in which art is embodied in these territories. To this end, I present the study of the Province of Buenos Aires still as an incognita. Secondly, I introduced the context of the organization. And finally, I analytical and empirical tensions in the productions and interventions of the chosen actors. The ultimate purpose of this paper is to contribute to the debates on artistic productions in the urban peripheries, trying to transcend those that exhaust the understanding of art under the conceptions of "the aesthetic" and "the legitimate".

Keywords: conurbano; everyday life; art; inequality; Argentina

\section{INTRODUCCIÓN}

Producimos ciudades y en ese desplazamiento, muchas veces, reproducimos desigualdades. Aunque tal afirmación no es novedosa, si lo son los modos en que las prácticas artísticas y culturales comienzan a ser parte del repertorio de acciones que organizaciones sociales activan para desmontar imaginarios y estereotipos que tienden a estigmatizar estos contextos tanto como a las personas que allí residen.

En este artículo presento las características del Gran Buenos Aires, mayormente identificado como conurbano, bajo la invitación de analizar este lienzo geográfico como una «arena cultural» siguiendo de esta manera la propuesta de Adrián Gorelik y Fernanda Arêas Peixoto (2016). El fin último que organiza este texto es el de contribuir al desmonte de ciertos discursos estigmatizantes sobre la desigualdad social y, al mismo tiempo, dar cuenta de las variadas maneras desde las cuales las organizaciones sociales, arte mediante, dan cuenta de los problemas de sus contextos. De esta manera, no se trata de tomar el arte como fin sino como una herramienta, como parte de un desarrollo colectivo y participativo. En particular, presento las experiencias de la Biblioteca Popular La Cárcova $^{l}$ como parte de las acciones para desmontar imaginarios a la vez que para repensar el arte menos desde sus lugares de legitimación y circulación y más desde los

\footnotetext{
${ }^{1}$ Quién escribe forma parte de este proyecto de educación y cultura popular desde 2012 por eso la alternancia en la persona narrativa elegida para este escrito.
} 
modos complejos y diversos en que puede constituirse en una herramienta transformadora de la vida cotidiana.

La búsqueda final de este escrito es incomodar o más bien, lograr atravesar otros recorridos del arte, no ya en tanto hecho estético sacro y aislado sino más bien como una construcción colectiva situada, histórica y profundamente atravesada por el lugar desde donde se produce, independientemente de que las condiciones, los medios y las formas no sean las que se suelen juzgar como necesarias o adecuadas.

\section{CONURBANO EN CONTEXTO ${ }^{2}$}

El Gran Buenos Aires, geográficamente lindante con la Ciudad Autónoma de Buenos Aires (CABA), alberga de acuerdo con el último censo casi 10 millones de habitantes (Bruno, 2015). A pesar de no constituir una unidad administrativa específica, ella ha configurado parte de la historia nacional, de los relatos locales y de la vida de las personas. A menudo identificado por la literatura como Gran Buenos Aires ${ }^{3}$.Con características urbanísticas y sociales diversas, emerge como un collage (Zarazaga, 2017) de complejo acceso y comprensión en donde la desigualdad se convierte en uno de los lentes de observación posibles y, a menudo, recurrentes. Su rápido y descontrolado crecimiento tuvo como consecuencia la proliferación de imaginarios, más aún, de aquellas zonas que parecían alejarse del progreso económico y la expansión planificada.

\footnotetext{
${ }^{2}$ Algunas reflexiones de este apartado fueron elaboradas en un escritor anterior de la autora (Blanco Esmoris, 2018).

${ }^{3}$ Existe una amplia literatura respecto a la definición del conurbano, cuyos límites de acuerdo con el criterio utilizado, en algunos casos, suele variar la territorialidad considerablemente. Inicialmente, en el Censo de 1947, comenzó a utilizarse el término Gran Buenos Aires para referir a una unidad censal conformada tanto por la Ciudad Autónoma de Buenos Aires como por los municipios del Gran Buenos Aires que la rodean, en ese entonces 17, hoy 24 (Segura, 2015) también denominada Área Metropolitana de Buenos Aires (AMBA) (Informe INDEC, 2003). La Región Metropolitana de Buenos Aires (RMBA) remite al conglomerado urbano alrededor de la Ciudad Autónoma de Buenos Aires y comprende 40 municipiospartidos (Informe INDEC, 2003). En lo que refiere a aspectos urbanos y residenciales, la denominación Aglomerado Gran Buenos Aires (AGBA) resulta ser una denominación menos precisa y más amplia ya que se basa en el acceso móvil a diversos puntos de la ciudad resultando ser una "mancha urbana" en relación con la presencia de viviendas. El conurbano, si bien puede encuadrárselo en estas diversas denominaciones constituye un apelativo recurrente que muchas veces implica imprecisiones e incertidumbres respecto de la exactitud de lo que se denomina. En términos estrictos, y de acuerdo con un criterio jurídico-administrativo asentado en la Ley Provincial 13.473, el Conurbano Bonaerense está constituido por 33 municipiospartidos. Para una mayor precisión respecto del tema, véase: ¿Por qué el Conurbano? (Downes, 2015). En este trabajo utilizaremos, continuando con cierta tradición en la literatura académica consultada, de conurbano delimitado por los 24 municipios-partidos.
} 
A menudo, fue colocado como contrapunto a la Ciudad Autónoma de Buenos Aires que encarnó el tipo ideal» de desarrollo citadino al cual seguir.

Los límites entre la capital y la provincia se construyeron según una línea geométrica materializada, en la segunda mitad de la década de 1930, con la construcción de la avenida de circunvalación General Paz. Los mundos separados por dicha avenida tienen, según la zona, mayor continuidad o ruptura (Carman, 2015, p. 533).

Se trata de un territorio que a menudo ha sido percibido como una «incógnita» (Gorelik, 2015) tanto en su denominación como en su identidad pues al intentar capturarlo se fuerzan sus especificidades a la vez que se subliman sus clivajes. Una de sus características, tal vez, sea exceder y desbordar los cánones interpretativos y paradigmas teóricos de interpretación, que se convertían en empantanadas claves de análisis. Este espacio, a modo de hipótesis, se ha configurado como una suerte de "arena cultural" (Gorelik \& Arêas Peixoto, 2016) que ha tensado imaginarios, representaciones y formas históricas y específicas de ocupación y experiencia.

\section{PRODUCIR DESDE LUGARES “OTROS”: LA EXPERIENCIA ORGANIZANTE}

Trazar y cartografiar el conurbano significa pensar un mapa que parta de sus actividades, actores y relaciones. ¿De qué manera las personas significan no solo el espacio sino también sus entornos, herramientas y medios culturales? Esto nos lleva a una discusión puntual que tiene al conurbano como espacio de producción artístico/cultural que problematiza la idea del «arte» y «legítimo». Para esta reflexión, retomamos las ideas de Howard Becker (2008) quién aborda no sólo el arte como fenómeno social sino también como una forma de producción colectiva, haciendo foco en la dimensión cooperativa y colaborativa.

Las expresiones culturales vinculadas con el Gran Buenos Aires han sido estudiadas por las Ciencias Sociales en tanto productos (obras literarias, films y música, entre otras), es decir, en tanto obras acabadas, sin atender al proceso creativo en sí. De dicho proceso, a menudo, han participado organizaciones comunitarias, tales como 
asociaciones civiles, sociedades de fomento, centros culturales y bibliotecas populares (en relación con ellas, en efecto, según un relevamiento del Sistema de Información Cultural de la Argentina, para 2013 había un total de 170 en el conurbano bonaerense del [del Cueto \& Ferraudi Curto, 2015, p.572]). A estas formas de intervención, en los últimos años, se le suma el arte callejero con una abundante producción de graffitis y murales a lo largo, ancho y profundo del conurbano.

\section{Una organización: Biblioteca Popular La Cárcova}

El contexto de inscripción e influencia de la Biblioteca Popular es la localidad de José León Suárez, Municipio de San Martín ${ }^{4}$, específicamente lo que se conoce como el «área Reconquista de José León Suárez» ${ }^{5}$. Este territorio se caracteriza por una alta densidad poblacional que habita en «villas miserias» o «villas basurales». En Villa la Cárcova, que es el ámbito de inscripción de este proyecto, habitan unas 16 mil personas. Carece de asfalto, cloacas y red de gas, mientras que el agua potable y el servicio eléctrico están en precarias condiciones. La zona está expuesta a inundaciones, a cortes de luz y de agua permanentes. En la década del '90 se asentó el CEAMSE (Coordinación Ecológica Área Metropolitana Sociedad del Estado) con la idea de generar un "complejo ambiental" que pudiera "tratar" los residuos producidos en la ciudad de Buenos Aires y algunos municipios del Gran Buenos Aires de modo tal que volvieran al circuito productivo. El CEAMSE ha tenido un profundo impacto en la degradación de las condiciones de vida de las personas que habitan La Cárcova provocando que muchas familias sufran de contaminación física y ambiental. Fue a partir de la instalación de un basural que "la basura" emergió como un significante en la vida de los carcoveños; o bien, para pensar el basural como un lugar más en donde recolectar residuos informalmente - cirujeo $^{6}$-, comer las sobras o bien, para posicionarse críticamente sobre sus efectos. Como consecuencia, para quienes residen en las inmediaciones y bajo estas condiciones

\footnotetext{
${ }^{4}$ El Municipio de San Martín linda con la Ciudad Autónoma de Buenos Aires, al noroeste de esta. Fue fundado en 1864 y hoy en día posee más de 420 mil habitantes.

${ }^{5}$ El Río Reconquista es un río cuya cuenca abarca 18 municipios del AMBA, entre los cuales encontramos al Municipio de San Martín. En particular nos referimos sobre el área que abarca a la localidad de José León Suárez y sus aledaños inmediatos.

${ }^{6}$ Esta condición en muchos casos es autopercibida y en otros es el apelativo frecuente para denominar a la recolección informal de residuos que para muchos y muchas es considerado menos un rebusque o supervivencia y, más bien, se lo considera, siguiendo a Mariano Perelman (2014), un trabajo.
} 
sociales, el CEAMSE y el cirujeo constituyen parte de sus narrativas y prácticas. El basural no tiene un territorio limitado, sino que se extiende por el barrio, en las esquinas, la tierra, el aire y el agua, y trae como consecuencia inevitable enfermedades epidérmicas como forúnculos e irritaciones en la piel, y enfermedades pulmonares como broncoespasmos y tuberculosis. Esta población vive en y de la basura, ya que muchas familias «cirujean», se alimentan y comercializan los productos rescatados de la basura. Las condiciones materiales y sociales de este espacio hacen mella en la vida de las personas y su vinculación con los espacios colectivos y de producción de sentido.

La Biblioteca Popular La Cárcova fue una gesta iniciada en 2012 y desde entonces e in crescendo fue albergando diversas actividades vinculadas al apoyo escolar, la cultura y el arte en el barrio tanto como actividades deportivas y de oficio. Asimismo, se planteó como un espacio de contención y apoyo a personas expuestas a altos niveles de vulnerabilidad social de la villa y de zonas aledañas en la zona denominada «área Reconquista de Suárez». La gesta fue inicialmente llevada a cabo por Waldemar Cubilla junto a familiares y carcoveños que vieron la posibilidad de conformar un espacio que permitiese a los chicos acceder a libros, actividades, experiencias y formas de incorporarse a otros registros que o bien eran de difícil acceso o bien de dificultosa continuidad a causa de la falta de recursos y de tiempo o por la propia lejanía espacial. En la Biblioteca, hoy en día, hay en funcionamiento una serie de actividades, tales como talleres de percusión, fotografía, teatro, arte plástica, cerámica, arquitectura, hockey mixto y escuela de fútbol; también se realizan asistencia y contención a personas expuestas a alto niveles de vulnerabilidad económica y social; se ofrecen, además, talleres de formación profesional (albañilería, electricidad domiciliaria, herrería y carpintería). El alcance de las acciones involucra a unas 200 personas de todas las edades. Las actividades culturales de este espacio son un lugar de encuentro y aprendizaje a la vez que permiten la reunión de diversos actores del territorio y de la comunidad. Algunas de estas iniciativas están pensadas para ciertos grupos etarios mientras que en otras se intenta generar un diálogo intergeneracional. Uno de los objetivos de la institución consiste en desarrollar herramientas de formación y experiencia de diversos saberes que no entienden de distinciones entre lo «manual» y lo «intelectual» sino que implican una reflexión y una implicación del cuerpo constante y recurrente. Al mismo tiempo, la Biblioteca se presenta 
como una experiencia de continuidad frente a la vida fragmentaria que se manifiesta muy abruptamente en la vida de todos los que habitan Cárcova; fragmentaria en términos de relación con el Estado, con el sector privado, en sus vidas y también en la relación con su ciclo vital. Muchos de los carcoveños no acceden a bienes y servicios, a cobertura médica, a una educación continua y, ni siquiera, a la regularidad de los medios de transporte. En ese sentido, la Biblioteca fue pensada y practicada como un espacio reflexivo respecto de su emplazamiento en el conurbano en tanto lugar de posibilidad y de producción. Esta Biblioteca es reafirmada como un espacio vital quienes la componen.

Los nombres Villa La Cárcova y Biblioteca Popular La Cárcova se vinculan con una calle que atraviesa el territorio como también con el nombre del pintor, maestro y primer director de la Academia Nacional de Bellas Artes, Ernesto de La Cárcova quien, profundamente preocupado y movilizado por las condiciones de vida en Argentina alrededor de 1850 y principios del siglo XX, reflexionó en sus pinturas realistas sobre las desigualdades sociales y laborales en Argentina. Sea casual o causal, en esta articulación de experiencias se advierte como el arte y la cultura, son recursos sensibles a las problemáticas de la vida cotidiana. En particular, este artista puso acento en materializar las condiciones de vida consideradas marginales y periféricas. De alguna manera, la Biblioteca propone lo mismo desde su lugar de enunciación y sus proyectos artísticosculturales.

Algunas de estas experiencias surgidas en el marco de la Biblio se dieron en el espacio de arte. En el marco de este taller, acompañados por la profesora Florencia Miguel, hicieron del arte un lugar de encuentro tanto como una herramienta reflexiva en el Museo Nacional de Bellas Artes de la Ciudad de Buenos Aires. La visita al museo fue en el marco de la conmemoración de los 150 años del nacimiento de Ernesto de la Cárcova en dónde, una de sus piezas cautivo de una manera visceral a los chicos que asistieron a la actividad: "Sin pan y sin trabajo" es una de sus obras que a los chicos y chicas les permitió elaborar biográficamente su vínculo con el arte; entendiendo que esta pieza puso de manifiesto las trayectorias de desigualdad que enfrentan y viven los chicos que asisten a la Biblioteca. La experiencia de ir al Museo de Bellas Artes - una de las casas legitimadoras del arte argentino y regional por excelencia-, sentarse en el suelo y pintar 
esa obra a la luz de sus propios marcadores personales implicó un diálogo con su entorno biográfico y, es más, el trazo de una biografía colectiva (Grieco, 2016).

Otro de los itinerarios en el marco de la Biblioteca, es el ciclo anual de graffitis «Mi barrio no es basura» que justamente busca visibilizar un reclamo vinculado a la contaminación y violencia ambiental que día a día atraviesan los/as carcoveños/as; así como, las formas complejas de vincularse con la basura, ya que para muchos de ellos es un medio de supervivencia y de trabajo [1] mientras que, para otros, remite a la contaminación y afección corporal que produce. Esta jornada de pintada es colectiva y, previo y durante la pintada, se van conversando aquellas cosas que se quieren hacer (qué pintar, en dónde, con qué colores); todo esto implica una reflexividad que se ejerce en la práctica. En efecto, estas experiencias locales constituyen una «arena»o «arenas culturales», es decir, lugares de confluencia, desmarcamiento y también de diálogo y disputa. Como una suerte de intersticio entre lo que deja huella y lo que se borra.

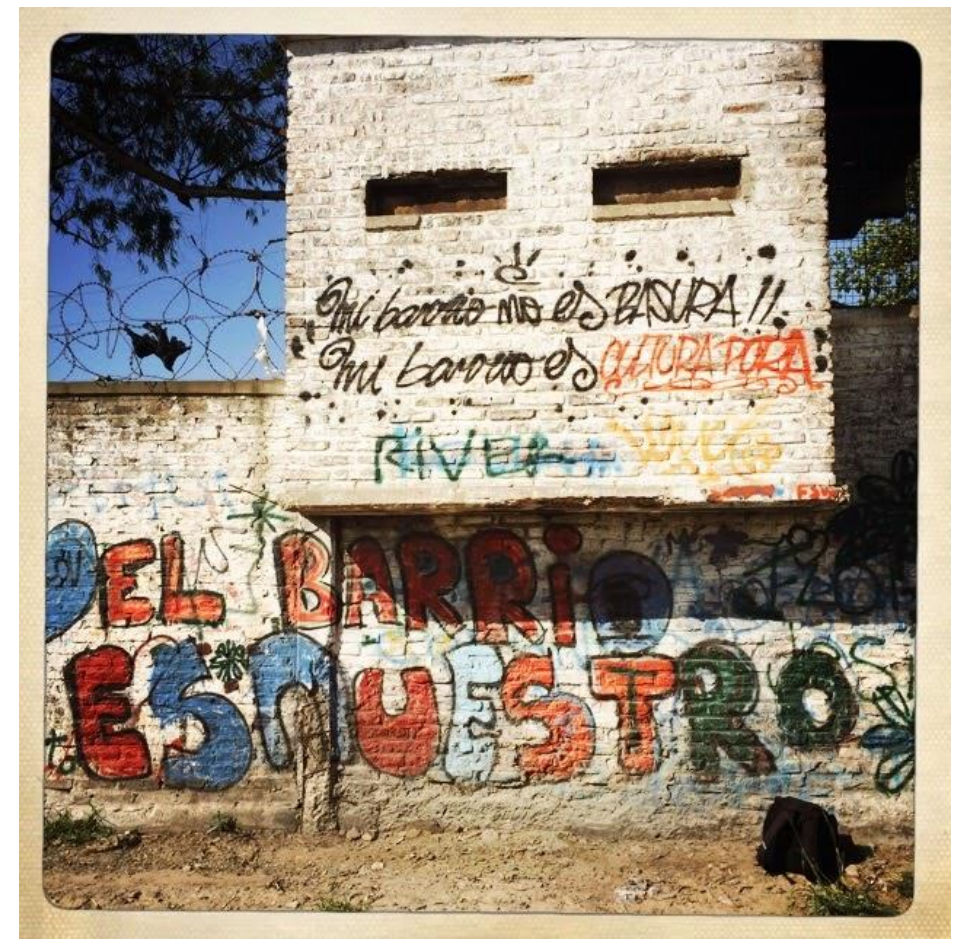

1. Imagen del mural durante la jornada "Mi barrio no es basura". Fuente: Blog Biblioteca Popular La Cárcova. 


\section{Hacer territorio la pared: el arte mural}

Hacer, marcar, texturar y componer un mural también es hacer territorio. Los modos en que hacemos de los espacios lugares implican, en algunos casos, incorporarse a una «arena cultural» (Gorelik \& Arêas Peixoto, 2016) que siempre está deviniendo.

Quienes formamos parte de la Biblioteca Popular decidimos ya hace tiempo incorporarnos a las muchas arenas que implican disputar lo normalizado y normalizante tanto para el sentido común como para ciertas miradas académicas. En este caso, el conflicto, no es entendido como un cierre a las posibilidades de acción, de comunicación colectiva sino más bien una apertura al intercambio. La experiencia artística se hizo cuerpo en la Biblioteca Popular La Cárcova cuando el sábado 15 de diciembre de 2018 chicos/chicas, jóvenes y adultos/as nos reunimos a compartir una jornada de arte mural colectivo. Año a año desde la Biblioteca Popular invitamos a la comunidad a pintar algo significativo respecto del espacio popular que estamos construyendo: una búsqueda, una expresión de deseo, exponer alguna problemática o materializar alguna característica particular de nuestro año como organización popular. El antecedente de esta jornada mural fue el ciclo de graffiti denominado "Mi barrio no es basura" dicho encuentro anual reunía a graffiteros/as de diversos barrios a poner en los muros de las inmediaciones de Cárcova mensajes y palabras respecto de una problemática nodal en Cárcova: la basura. Dicha jornada anual comenzó a consolidarse como un lugar de enunciación de la Biblioteca como antesala de muchos espacios artísticos que luego se motorizaría en la organización.

Este año, la jornada comenzó meses atrás cuando Florencia Miguel Mussari, profe de artes visuales y encuadernación -y de tantos otros talleres en «la Biblio»-, junto a Analía Hertz, de la organización comunitaria Pinta Mestiza, comenzaron a pensar esta idea de proponer una jornada mural que, en esta oportunidad, quedaría en las paredes de la Biblioteca. De este modo, Analía y Florencia colocaron un afiche como ideario del mural así todas y todos escribieron, imaginaron y volcaron palabras y frases sobre este. El afiche se llenó con diversas tintas y palabras que cristalizan el día a día de la organización como ser: música, libros, chocolatada, encuentros, guitarras, tambores, unidad, comunidad, libertad, pero una llamaba la atención de quienes miraban el afiche: 
"trabajo de hormiga". Esa continuidad cotidiana casi imperceptible de un trabajo que deja huellas, marcas y atraviesa e interrumpe la vida de las personas en estos territorios. Ese afiche de construcción colectiva fue la antesala del boceto de la jornada mural [2].

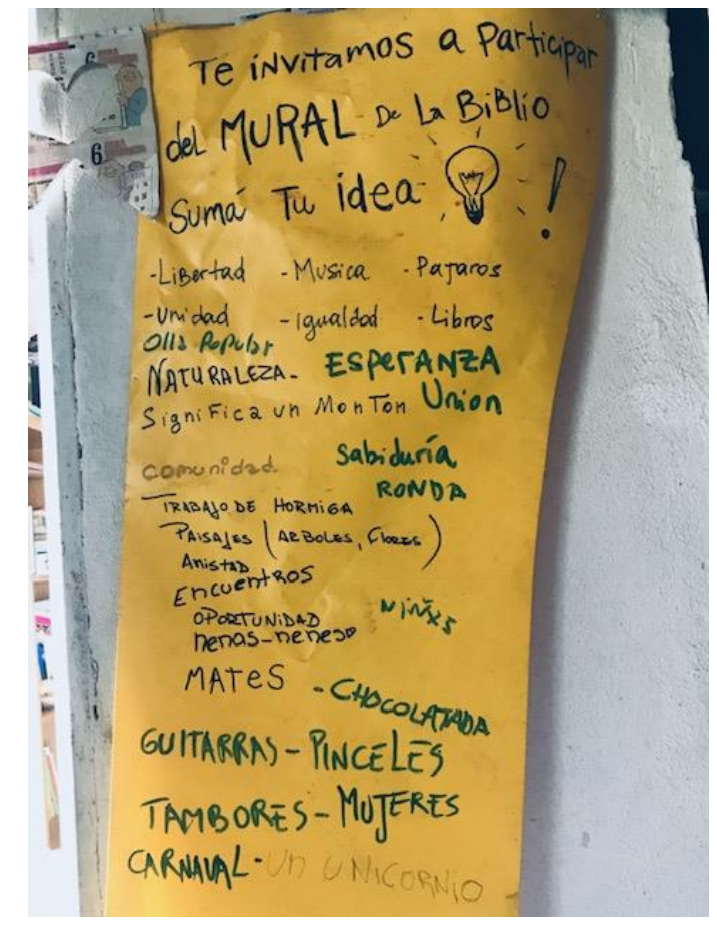

2. Afiche-boceto del Mural colectivo. Fuente: archivo propio

El sábado 15 desde temprano junto a Flor y Analía, entre pinceles, latas de pintura, mucha ansiedad que junto a los niños y niñas y jóvenes que comenzaban a llegar a «la Biblio», empezamos la jornada mural. Poco a poco se realizaron otras actividades, se cortaron calles, se dispusieron mesas con cuentos para que los chicos y las chicas puedan leer también hojas para que sigan pintando y creando y, aparecieron notas musicales tanto de folclore como de rap de artistas locales [Fig. 3]. La bandera de La Biblioteca flameaba y la pintura en ese mural se secaba para afirmarse, volvía cuerpo una expresión de libertad, un modo de ser de una organización social, pero por sobre todo la puesta en escena de una construcción colectiva y popular. A medida que caía la tarde llegaba más gente, a ver que sucedía o a colaborar con la jornada mural. El barrio congregaba, era motivo de re-encuentros, miradas, abrazos acalorados y mucho amor. Ese muro de nuestra Biblioteca sostenido por hormigas, libros, tambores, personas y vínculos constituye parte del acervo del barrio carcoveño y parte de cada trayectoria local [Fig. 4]. 


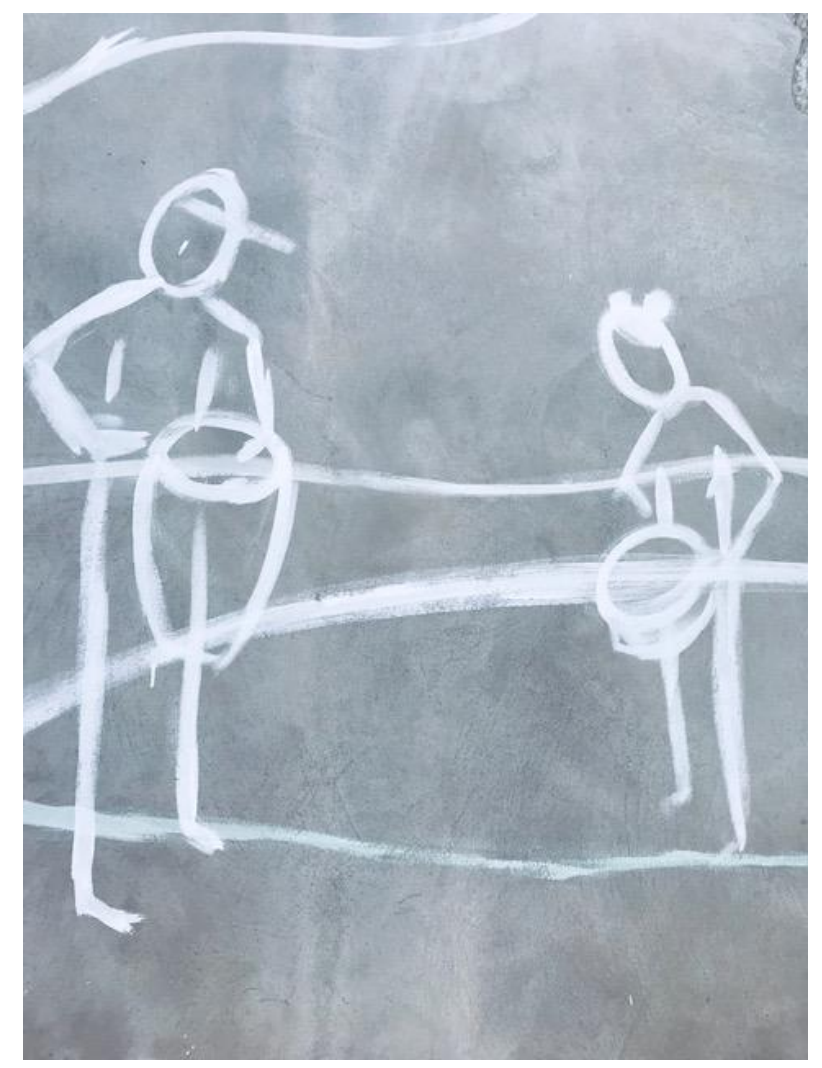

3. Boceto en la pared. La musicalidad colectiva. Fuente: archivo propio

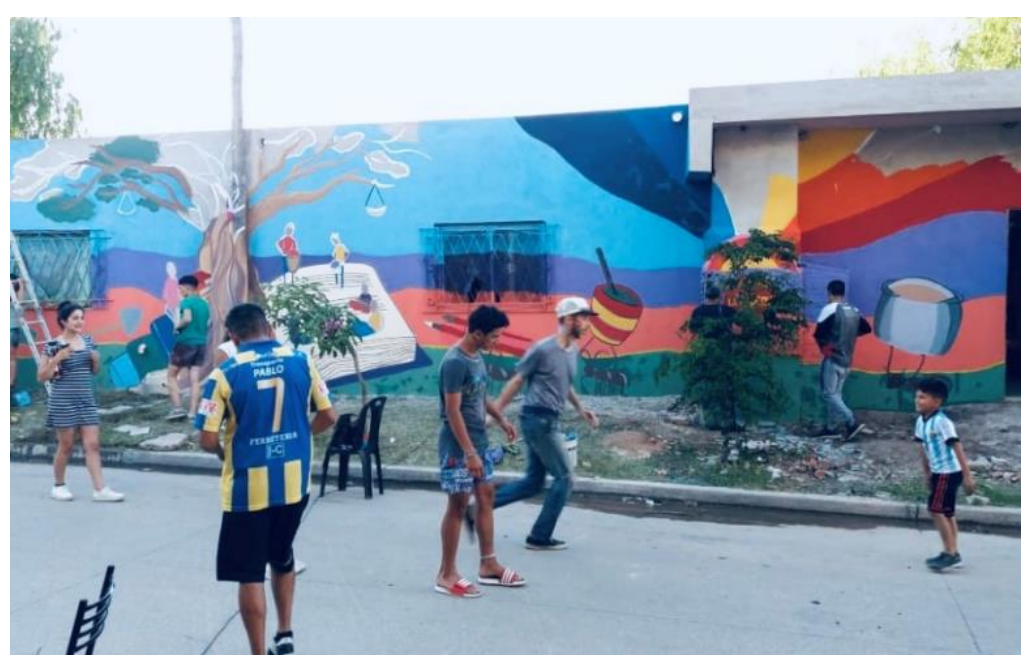

4. Imagen del devenir del evento. Fuente: archivo propio 


\section{CONCLUSIONES}

La referencia inicial a la noción de "arenas culturales" de Gorelik \& Arêas Peixoto (2016), retomada de la categoría de Morse y Hardoy (Gorelik \& Arêas Peixoto, 2016, p. 11), tuvo como intención presentar un lugar de enunciación. Lugar que, a lo largo del escrito, fue transitando "modalidades" en las que la cultura en el Gran Buenos Aires "permite una comprensión compleja e integral tanto de la ciudad como de la cultura misma". En este sentido, este trabajo introdujo precisiones teórico-analíticas respecto al Gran Buenos Aires, así como características de las trayectorias y de las producciones artísticas de una organización cultural-comunitaria (Biblioteca Popular La Cárcova). En donde, implícitamente, retomamos un interrogante respecto a «¿en qué medida el análisis de la cultura urbana es capaz de iluminar ese proceso de interpenetración y correspondencia entre ciudad y cultura?»(Gorelik \& Arêas Peixoto, 2016, pp. 12-13).

El fin último que, aun en desarrollo, persigue esta comunicación es contribuir a los debates respecto a las producciones artísticas «en y desde las periferias urbanas» intentando trascender a aquellos que agotan el entendimiento sobre el arte bajo las concepciones de «lo estético»y «lo legítimo». Justamente, la arena implica desbordes, marcas y huellas, pero también la discusión de lo arraigado en un grano de arena.

Las condiciones locales dan elementos para discutir los valores morales alrededor de la producción artística, teniendo en cuenta tanto la geografía e historia de quienes la actúan como su lugar de enunciación. El conurbano, para muchos de los actores que se presentaron en estas páginas, resulta ser un lugar de enunciación mediato y necesario a la vez que, la villa y/o el barrio el inmediato. Este texto se comprende en el marco de una búsqueda por entender el "acto creativo" en los términos en que es significado por las personas. Ahora bien, el problema descansa en aun seguir reflexionando estas acciones en términos de falta o carencia. 


\section{REFERENCIAS BIBLIOGRÁFICAS}

Biblioteca Popular La Cárcova (24 de noviembre 2014). Recuperado de http://bibliotecapopularlacarcova.blogspot.com.ar/

Blanco Esmoris, María. Florencia. (2018), “Entre el acto y la experiencia: 'el arte' en las producciones artístico-visuales localizadas en las periferias urbanas del Gran Buenos Aires, Argentina”. En Chaves Martin, M.A. (Ed.). Narrativas Urbanas (pp. 597-608). Madrid, Grupo de Investigación Arte, Arquitectura y Comunicación en la Ciudad Contemporánea (UCM).

Becker, Howard (2008). Los mundos del arte. Sociología del trabajo artístico. Universidad Nacional de Quilmes: Bernal.

Bruno, Matías (2015), “La población del conurbano en cifras”. En Kessler, G. (Dir). Historia de la provincia de Buenos Aires: El Gran Buenos Aires (pp. 159-191). Ciudad Autónoma de Buenos Aires, Edhasa, Gonnet, UNIPE Editorial Universitaria.

Carman, María (2015), “Cercanías espaciales y distancias morales en el Gran Buenos Aires”. En Kessler, G. (Dir). Historia de la provincia de Buenos Aires: El Gran Buenos Aires (pp. 521-547). Ciudad Autónoma de Buenos Aires, Edhasa, Gonnet, UNIPE Editorial Universitaria.

Del Cueto, Carla y Ferraudi Curto, Cecilia (2015), "Made in conurbano. Música, cine y literatura en las últimas décadas”. En Kessler, G. (Dir). Historia de la provincia de Buenos Aires: El Gran Buenos Aires (pp. 549-577). Ciudad Autónoma de Buenos Aires, Edhasa, Gonnet, UNIPE Editorial Universitaria.

Downes, Juan Carlos (2015). ¿Por qué el Conurbano?. Dukuen: Ciudad Autónoma de Buenos Aires.

El Chicu, Noticiero interno y externo (1 de noviembre de 2017). Entrevista a Waldemar Cubilla - Biblioteca Popular La Cárcova [Archivo de video]. Disponible en https://www.youtube.com/watch?v=p7x90TmWBvw

Gorelik, Adrián (2015). “Terra incognita. Para una comprensión del Gran Buenos Aires”. En Kessler, G. (Dir). Historia de la provincia de Buenos Aires: El Gran Buenos Aires (pp. 21-69). Ciudad Autónoma de Buenos Aires, Edhasa, Gonnet, UNIPE Editorial Universitaria. 
Gorelik, Adrián \& Areas Peixoto, Fernanda (Comps.) (2016). Ciudades Sudamericanas como arenas culturales. Siglo Veintiuno Editores: Buenos Aires.

Grieco, Gaspar (1 de noviembre de 2016). La UNSAM y el MNBA homenajean a Ernesto de la Cárcova a 150 años de su nacimiento. Recuperado de: http://noticias.unsam.edu.ar/2016/11/01/la-unsam-y-el-mnba-homenajean-a-ernesto-dela-carcova-a-150-anos-de-su-nacimiento/

Informe INDEC (2003), ¿Qué es el Gran Buenos Aires?. Recuperado de: https://www.indec.gob.ar/dbindec/folleto_gba.pdf

Perelman, Mariano (2014), "Viviendo el trabajo. Transformaciones sociales, cirujeo y venta ambulante". Trabajo y Sociedad, no 23 (invierno), pp.45-65. Recuperado de: https://www.unse.edu.ar/trabajoysociedad/23\%20PERELMAN\%20Cirujeo\%20y\%20ve nta\%20ambulante.pdf

Segura, Ramiro (2015). "La imaginación geográfica sobre el conurbano. Prensa, imágenes y territorio”. En Kessler, G. (Dir). Historia de la provincia de Buenos Aires: El Gran Buenos Aires (pp. 129-157). Ciudad Autónoma de Buenos Aires, Edhasa, Gonnet, UNIPE Editorial Universitaria.

Zarazaga, Rodrigo y Ronconi, Lucas (2017). Conurbano infinito. Actores políticos y sociales, entre la presencia estatal y la ilegalidad. Siglo Veintiuno Editores: Buenos Aires. 